\title{
KONSEP SMART TOURISM SEBAGAI IMPLEMENTASI DIGITALISASI DI BIDANG PARI- WISATA
}

\author{
Fauziah Hanum1, Dadang Suganda2, Eng. Budi Muljana3, Cipta Endyana4, Heryadi Rachmat5 \\ 12345Sekolah Pascasarjana, Universitas Padjajaran, Jl. Dipatiukur No. 35 \\ fauziah19003@unpad.ac.id,
}

\begin{abstract}
Abstrak. Perkembangan teknologi membuat wisatawan di era milenial ini semakin cerdas, sadar dan melek teknologi sehingga menimbulkan persaingan yang ketat pada setiap bidang khususnya Pariwisata. Perlu adanya terobosan baru secara berkala agar dapat bertahan. Salah satu cara untuk meningkatkan industri pariwisata adalah dengan memanfaatkan kemajuan teknologi informasi dan komunikasi. Konsep Smart Tourism merupakan hasil dari pengembangan inovasi teknologi dan informasi tersebut. Penelitian ini merupakan penelitian kualitatif dengan metode deskriptif. Tujuan dari penelitian ini adalah mengetahui bagaimana secara lebih jelasnya mengenai bagaimana konsep smart tourism tersebut dan bagaimana bentuk pemanfaataanya dalam bidang pariwisata. Data diperoleh melalui kajian literatur dari berbagai artikel jurnal baik itu dalam dan luar negeri sebagai bahan dan pembanding. Hasil penelitian menunjukan bahwa Penerapan konsep smart tourism yang berbasis teknologi merupakan solusi terbaik bagi semua pihak. Selain itu pengaplikasian konsep smart tourism dapat membawa pengalaman wisata yang lebih baik, kesejahteraan penduduk, meningkatkan efektivitas - daya saing - tujuan bisnis dan selanjutnya akan mengarah pada keberlanjutan yang kompetitif secara keseluruhan.
\end{abstract}

Kata kunci; smart tourism, digitalization, 4.0

\section{SMART TOURISM CONCEPT AS A IMPLEMENTATION OF DIGITALIZATION ON TOURISM}

\begin{abstract}
The development of technology makes tourists in this millennial era increasingly intelligent, conscious and technological literacy, giving rise to intense competition in every field especially tourism. There needs to be a regular new breakthrough to survive. One way to improve the tourism industry is to utilize the advancement of information and communication technology. The Smart Tourism concept is the result of developing technological innovations and information. This research is a qualitative study with descriptive methods. The purpose of this research is to know how more details about how the smart tourism concept is and how it is the utilization of tourism in the field. Data is obtained through literature studies of various journal articles both in and out of the country as materials and comparators. The results showed that the implementation of the technology-based smart tourism concept is the best solution for all parties. In addition to the application of smart tourism concept can bring better tourist experience, welfare of the population, increase the effectiveness-competitiveness-business objectives and lead to the overall competitive sustainability.
\end{abstract}

Key words; smart tourism, digitalization, 4.0

\section{PENDAHULUAN}

Di era digitalisasi ini, tren masyarakat berubah dengan sangat cepat dikarenakan mudahnya akses untuk mencari informasi. Bidang Pariwisata sebagai salah satu industri yang perkembangannya pesat tentulah terus berubah mengikuti tren yang sedang berlangsung. Sektor pariwisata butuh untuk beradaptasi dengan cepat terhadap lingkungan dan persaingan yang ketat (Gajdosik, 2018). Smart tourism adalah langkah terbaik untuk bertahan dalam kerasnya evolusi teknologi dan informasi dimana dimensi fisik dan pemerintahan pariwisata memasuki tingkat selanjutnya (digitalisasi) sehingga tercapainya sebuah generasi baru yang lebih modern sesuai dengan perkembangan jaman (Gajdosik, 2018).

Smart tourism sebagai ekosistem baru dapat mendukung dan memfasilitasi penciptaan inovasi baru khususnya yang berhubungan dengan pengaplikasian teknologi dan pengembangan pengalaman wisata yang cerdas (Femenia-Serra \& Neuhofer, 2019). Konsep smart tourism lahir dari pengembangan kajian mengenai hubungan teknologi dan bidang pariwisata (Gajdosik, 2018). Smart Tourism dapat menggambarkan situasi terkini mengenai bagimana pengembangan dalam bidang pariwisata juga telah terpengaruh oleh evolusi dari pesatnya perkrmbangan teknologi dan informasi (Gajdosik, 2018) Hal ini juga membuat dan menjembatani serta menyatukan usaha- usaha mikro dari masarakat setempat dan nomaden yang ada di daerah kepada pasar global (Gantemur, n.d.).

Konsep smart dalam smart tourism merupakan hasil dari pengembangan inovasi teknologi dan informasi (Gajdosik, 2018). Smart Tourism adalah pemanfaatan segala potensi dan sumber daya yang ada untuk meningkatkan pengalaman di bidang Pariwisata. Smart Tourism sebagai sebuah solusi menawarkan pembukaan berbagai ragam bisnis dengan lokasi yang menyebar sehingga dapat menjadi peluang untuk terbukanya banyak lapangan pekerjaan (Gantemur, n.d.). Smart Tourism merupakan perpanjangan langsung dar konsep e-tourism (Gajdosik, 2018). Konvergensi konten Pariwisata, layanan, dan 
perangkat IT yang membantu wisatawan untuk memperpanjang batas kognitif dari rencana perjalanan mereka dengan detail mengenai destinasi yang tervisualisasi dan meningkatlan kualitas terkait lainnya (Widjaja et.al, 2016). Tujuan dari smart tourism adalah fokus untuk pemenuhan kebutuhan wisatawan dengan menggabungkan perkembangan ICT dengan budaya serta inovasi untuk mempromosikan, meningkatkan kualitas layanan pariwisata, meningkatkan manajemen pariwisata dan memperbesar skala industri menjadi yang lebih luas (Buhalis \& Amaranggana, 2014).

Konsep Smart Tourism sendiri masih belum banyak didefnisikan secara lengkap dan spesifik dalam berbagai penelitian terdahulu, hingga kini belum banyak referensi yang membahas secara mendalam mengenai hal ini. Namun secara umum, definisi Smart Tourism dapat dari beberapa sumber adalah sebagai berikut:

TABEL 1

\section{DEFINISI SMART TOURISM}

\begin{tabular}{|c|c|c|}
\hline No & Nama Ahli & Definisi \\
\hline 1. & $\begin{array}{l}\text { Jimin Lee, Hanna } \\
\text { Lee, Namho Chung } \\
\text { and Chulmo Koo } \\
\text { (2017) }\end{array}$ & $\begin{array}{l}\text { Tren dan berbagai kreatifitas } \\
\text { menggunakan teknologi untuk } \\
\text { berbagai keuntungan: } \\
\text { memaksimalkan sumber daya, } \\
\text { manajemen yang efektif, destinasi } \\
\text { yang berkelanjutan, dan hidup } \\
\text { yang menjadi lebih berkualitas. }\end{array}$ \\
\hline 2. & $\begin{array}{l}\text { C. Derrick Huan, } \\
\text { Kichan Nam Jahyun } \\
\text { Goo, and Chul Woo } \\
\text { Yoo } \\
(2016)\end{array}$ & $\begin{array}{l}\text { Semua bentuk aplikasi online } \\
\text { Pariwisata dan sumber informasi } \\
\text { seperti online travel agent, blog } \\
\text { pribadi, situs web publik, webste } \\
\text { perusahaan, sosial media, aplikasi } \\
\text { pada smartphone, dan lain } \\
\text { sebagainva. }\end{array}$ \\
\hline 3. & $\begin{array}{l}\text { (Benckendorf et al, } \\
\text { 2014) }\end{array}$ & $\begin{array}{l}\text { Smart Tourism adalah suatu cara } \\
\text { untuk memperoleh informasi } \\
\text { tentang pariwisata dengan } \\
\text { memanfaatkan ICT }\end{array}$ \\
\hline 4. & (Su et al, 2011) & $\begin{array}{l}\text { Smart Tourism adalah } \\
\text { pemanfaatan platform hardware } \\
\text { dan software untuk informasi dan } \\
\text { layanan smart city yang } \\
\text { dimanfaatkan dengan baik untuk } \\
\text { menuju pasar pariwisata terpadu }\end{array}$ \\
\hline
\end{tabular}

Smart Tourism adalah suatu cara untuk memperoleh informasi tentang pariwisata dengan

\section{METODE}

Penelitian ini adalah studi kualitatif dengan metode deskriptif. Data untuk penelitian ini dikumpulkan melalui studi literatur baik itu dari artikel-artikel jurnal dalam dan luar negeri. Studi literatur ini dilakukan sebagai dasar dan bahan untuk merumuskan apa dan bagaimana konsep smart tourism tersebut sebagai implementasi teknologi di bidang pariwisata.

\section{HASIL DAN PEMBAHASAN}

Smart tourism di definisikan sebagai tahapan terkini dari pengembangan pariwisata yang dipengaruhi oleh evolusi dari perkembangan teknologi dan informasi (Gajdosik, 2018). Smart tourism adalah segala pemanfaatan ICT untuk memperoleh informasi yang berhubungan dengan kegiatan pariwisata (Okty, 2017). Smart tourism mengatur dan menyampaikan pengalaman serta jasa dalam kepariwisataan dengan pintar (memanfaatkan teknologi) yang dihasilkan oleh stakeholders yang tergabung dalam ekosistem smart tourism seperti produsen, distributor, wisatawan itu sendiri, agen pemerintah, agen perjalanan dan pelaku memanfaatkan ICT

4.(Su et al, 2011) Smart Tourism adalah pemanfaatan platform hardware dan software untuk informasi dan layanan smart city yang dimanfaatkan dengan baik untuk menuju pasar pariwisata terpadu

Komponen Utama Pembentuk Konsep Smart Tourism

Hal utama yang menjadi daya tarik dan mempengaruhi perilaku dan minat wisatawan sehingga menjadi tertarik untuk beralih mencoba Smart Tourism ini adalah pengalaman. Komponen- komponen utama dalam Smart Tourism adalah sebagai berikut (Guo et al, 2014):

- IoT

- Mobile communication

- Cloud computing

- Artificial intelegence

Namun adapula yang berpendapat bahwa yang membentuk smart tourism adalah sebagai berikut (Femenia-Serra \& Neuhofer, 2019):

- Data centrality

- Real time development

- Based on context-awareness

- Co-created

- Cross cutting issues

Pengembangan konsep smart tourism tentulah tidak dapat dipisahkan dari teknologi, sehingga banyak dilakukan penelitian mengenai hal tersebut. Jimin Lee, Hanna Lee, Namho Chung and Chulmo Koo pada artikel jurnal yang berjudul An Integrative Model of the Pursuit of Happiness and the Role of Smart Tourism Technology: A Case of International Tourists in Seoul merumuskan bahwa dimensi untuk variabel smart tourism technology ada 4 dimensi, seperti yang tergambar dibawah ini:

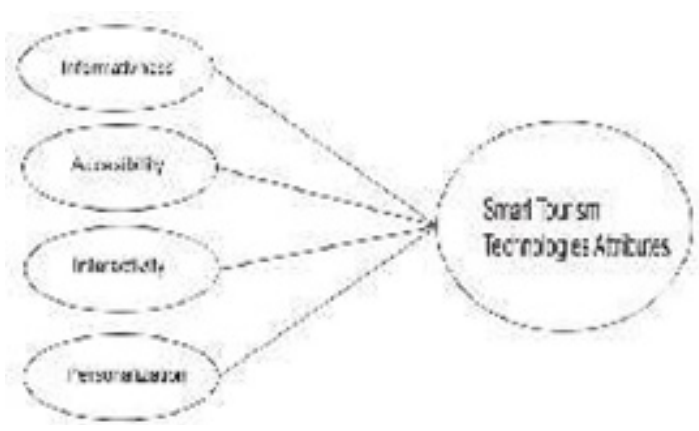

Sumber: (Lee et al., 2017)

GAMBAR 1

DIMENSI SMART TOURISM TECHNOLOGY 
Berikut adalah penjelasan singkat mengenai dimensi-dimensi dari smart tourism technology:

a) Informativeness: Bagaimana informasi yang diberikan oleh smart tourism technology ini dapat berguna, terpercaya, atau bernilai bagi pengguna selama digunakan dalam perjalanan.

b) Accesibility: Bagaimana kemudahaan akses yang dirasakan oleh pengguna smart tourism technology selama pemakaian.

c) Interactivity: Bagaimana interaksi yang terjadi atau dirasakan oleh pengguna smart tourism technology selama pemakaian.

d) Personalization: Bagaimana pengguna diberikan kebebasan untuk mengatur tampilan smart tourism technology ini sesuai dengan yang diinginkannya.

\section{Penerapan Konsep Smart Tourism}

Penerapan smart tourism memicu tingginya kebutuhan infrastruktur dan konsentrasi sumber daya dan penggunaan hal lainnya. Hal ini menjadi peluang untuk dimanfaatkan menuju kegiatan pengelolaan dan pasar pariwisata terpadu, tempat wisata, penyedia informasi dan layanan yang relevan dari perusahaan untuk promosi pengembangan pariwisata (Nindyati, 2017). Oleh karena itu dikembangkanlah alat-alat untuk menunjang kegiatan smart tourism ini.

Smart Tourism Destination Tools memungkinkan wisatawan untuk menggunakan ponsel mereka dalam menjelajahi atau eksplorasi destinasi. Pengguna yang dibantu oleh teknologi Smart Tourism Destination Tools dapat menavigasi perjalanan mereka tanpa menggunakan peta atau buku panduan wisata (Yeoman \& Yu, 2012). Bentuk smart tourism destination tools dapat terbagi menjadi tiga bentuk (Rusmin, 2018) yaitu:

\section{Aplikasi}

Apps terbagi menjadi 3 (tiga) jenis berdasarkan On dan Offline-nya yaitu "Native Apps", "Mobile Web Apps" dan "Hybrid Apps.

Native apps: aktif di perangkat fisik dan diakses melalui ikon di layar pada perangkat. Native Apps dapat memberikan referensi untuk wisatawan, yang sangat bermanfaat dalam menjaga biaya pada saat roaming secara rendah serta dapat mengakses informasi tanpa akses internet.

Web apps: merupakan situs web yang dalam banyak hal terlihat dan terasa seperti aplikasi asli.

Hybrid apps: sebagian web apps dan sebagian native apps. Mirip dengan native apps, aplikasi ini terdapat di toko aplikasi (apps stores) dan dapat memanfaatkan fitur perangkat.

\section{Augmented Reality (AR)}

Salah bentuk aplikasi yang penggunaannya sangat bergantung pada kebutuhan perangkat keras tambahan, dalam hal ini kamera inbuilt dari perangkat mobile (memberikan informasi melalui bentuk pencitraan). AR memungkinkan destinasi pariwisata untuk menciptakan pengalaman unik bagi wisatawan, terutama bila digabungkan dengan kegiatan wisata budaya. Kedepannya juga dapat dikembangkan untuk dilakukan penciptaan bersama terkait pengalaman dengan melibatkan wisatawan secara aktif untuk menjadi bagian dari hal ini.

\section{Near Field Communication (NFC)}

NFC adalah protokol komunikasi radio nirkabel jarak dekat yang mentransmisikan data yang disimpan di dalamnya ke perangkat elektronik. NFC dapat digunakan di tempat-tempat wisata seperti museum (wisatawan dapat memindai informasi di lukisan/patung/artefak sejarah melalui telepon mereka yang memunculkan misalnya terjemahan dalam bahasa asli atau sesuatu yang menjadi pengalaman baru). NFC juga dapat dimanfaatkan di hotel misalnya memudahkan untuk masuk ke kamar karena scan pintu menggunakan NFC tinggal tap saja, membuka pintu keamanan hotel dan mengakses informasi tentang atraksi lokal.

Dari bentuk-bentuk smart tourism tools tersebut berikut adalah contoh lain dari penerapannya dalam industri:

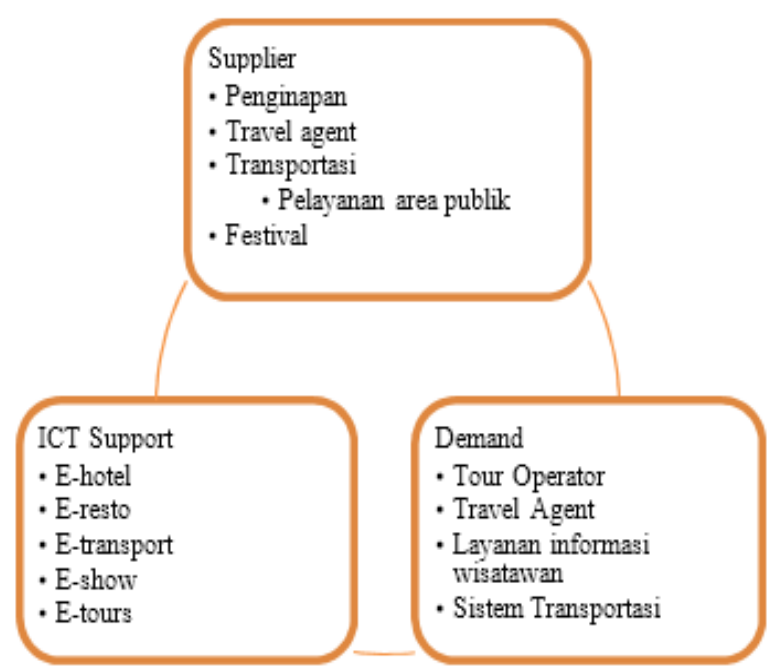

Sumber : (Nindyati, 2017).

GAMBAR 2

\section{CONTOH IMPLEMENTASI SMART TOURISM}

\section{Indikator Terlaksananya Konsep Smart Tourism}

Berikut adalah beberapa indikator telah terlaksananya penerapan konsep smart tourism menurut Nindyati (2017):

- Meningkatnya kenyamanan wisatawan baik domestik maupun mancanegara

- Sesuai dengan personalized demand dari wisatawan

- Munculnya common sharing

- Penggunakan berbagai sumber daya pariwisata dan budaya secara efektif dan intensif

- Adanya peran dan dukungan dari masyarakat 


\section{SIMPULAN}

Penerapan teknologi pada kegiatan kepariwisataan merubah pengalaman konsumen dan menghasilkan model bisnis pariwisata kreatif. Penerapan konsep Smart Tourism ini memungkinkan wisatawan untuk berkomunkasi dan berinteraksi dengan lebih baik serta mengacu pada perkembangan ekonomi pariwisata yang cerdas. Kegiatan smart tourism ini juga dapat menunjang dan mendukung pengembangan kota. Dengan menerapkan konsep smart tourism pada kebutuhan sebelum, saat dan sesudah kunjungan yang dilakukan wisatawan, maka industri atau bidang tersebut akan mendapat nilai kompetitif yang lebih di mata wisatawan. Selain itu, pengaplikasian konsep smart tourism dapat membawa pengalaman wisata yang lebih baik, kesejahteraan penduduk, meningkatkan efektivitas - daya saing - tujuan bisnis dan mengarah ke keberlanjutan yang kompetitif secara keseluruhan Pengembangan penggunaan teknologi (berbentuk aplikasi) memudahkan dan menyenangkan bagi wisatawan karena mereka merasa memiliki kebebasan untuk memilih dan mengatur hal yang diinginkannya dan menguntungkan industri (baik destinasi, perhotelan, restoran/kuliner, serta bidang lainnya) karena dapat mengurangi biaya promosi dan mempercepat proses transaksi. Hal ini menjadi keuntungan yang menyenangkan bagi semua pihak.

\section{DAFTAR PUSTAKA}

Buku dan Artikel Jurnal:

Ali, Baginda Syah (2016). Strategi Pengembangan Fasilitas Guna Meningkatkan Data Tarik Minat Wisatawan di Darajat Pass. Repository UPI

Buhalis, D., \& Amaranggana, A. (2014). Smart tourism destinations. Dublin: IFITT.

Femenia-Serra, Fransisco \& Neuhofer, Barbara. 2019. Smart Tourism Experiences: Conceptualisation, Key Dimension adn Research Agenda. Investigaciones Regionales - Journal of Regional Research, 42 (2018) Pages 129 to 150

Gantemur, D. (n.d.). The Investment Policy for enforcing the Nomadic Tourism.

Gajdosik, Tomas. 2018. Smart Tourism: Concepts and Insights from Central Europe. Czech Journal of Tourism. Vol 1.

Gretzel, Lina Zhong, Chulmo Koo. 2016. Application of smart tourism to cities. International Journal of Tourism Cities. Vol 2 Issue : 2. Emerald Group Publishing Limited.
Guo, Yang., Liu, Hongbo \& Chai, Yi. 2014. The Embedding Converegence of Smart Cities and Tourism Internet of Things in China. An Advance Perspective. An International Journal of Akademiz University Tourism Faculty. ISSN 2147-9100. Vol 2 Issue I - Pages 54-69.

Lee, J., Lee, H., Chung, N., \& Koo, C. (2017). An Integrative Model of the Pursuit of Happiness and the Role of Smart Tourism Technology : A Case of International Tourists in Seoul. Information and Communication Technologies in Tourism. http://doi.org/10.1007/978-3319- 51168-9

Mahadewi, Ni Made Eka., Negarayana, L.B Putra., Tirtawati, Ni Made \& Dianasari, D.A.M Lily. 2016. Persepsi Wisatawan Terhadap Bali

Sebagai Smart Tourism Destination. Experiment Finding.

Nindyati, Okty. 2017. Smart Tourism and Culture. https://www.slideshare.net/pinkylope/smart- tourism-and-culture

Park, Ji Hoon., Lee, Cheolhan., Yoo, Changsok \& Nam, Yoonjae. 2016. An analysis of the utilization of Facebook by local Korean Governments for Tourism development and the network of smart tourism ecosystem. International Journal of Information Management.

Smith, Richard. (2015). Smart Tourism: Linking technology with the touristic resources of city destination. NHTV University of Applied Sciences, Breda

Vallino. Interactive Augmented Reality," Ph.D. Thesis, Department of Computer Science, University of Rochester, Rochester, NY

Werthner, H \& Ricci, Franceso. 2004. E-commerce and tourism. Journal Communication of The ACM.

Yeoman, I., \& Yu, R. L. (2012). 2050 - Tomorrow's Tourism: Edinburgh 2050: Technological Revolution. Aspects of Tourism. Buffalo: Channel View Publications.

Widjaja, Andree E., Hery \& Tarigan, Riswan E. 2016. Meningkatkan Potensi Pariwisata Danau Toba Melalui Konsep Smart Tourism : Aplikasi dan Tantangannya.

Website:

https://id.wikipedia.org/wiki/Realitas_tertambah\#cite

note-4

https://www.nngroup.com/articles/mobile-nativeapps/ 